\title{
Regional hippocampal differences in AKT survival signaling across the lifespan: implications for CA1 vulnerability with aging
}

\author{
TC Jackson ${ }^{1}$, A Rani ${ }^{1}$, A Kumar ${ }^{1}$ and TC Foster ${ }^{*, 1}$
}

Distinct neuronal populations differ by the degree of damage caused from cellular stress. Hippocampal neurons of area CA1 are especially vulnerable to several stressors that increase as age advances. We show here that survival signaling, as measured by activated protein kinase B (AKT), was significantly reduced in the nuclear CA1 region across the lifespan compared with CA3. In agreement with these findings, the pro-apoptotic protein and AKT nuclear substrate, forkhead box 03a transcription factor (FOXO3a), were significantly higher in CA1. Further, regional differences in PH domain and leucine-rich repeat protein phosphatase 1 (PHLPP1), a recently discovered inhibitor of AKT, inversely correlated with nuclear phosphorylated AKT at Ser473. Altogether, our data suggest that regional differences in nuclear levels of activated AKT may contribute to regional differences in hippocampal vulnerability and implicate PHLPP1 as a potential target for therapeutic intervention to improve hippocampal health.

Cell Death and Differentiation (2009) 16, 439-448; doi:10.1038/cdd.2008.171; published online 28 November 2008

Aging is associated with increased vulnerability to hippocampal cell death. ${ }^{1}$ Furthermore, aging-dependent diseases can target vulnerable neuron populations. Under these conditions, loss of select hippocampal neuron populations can compromise hippocampal function, contributing to age associated memory impairments.

Despite the similarity in cell type between the CA1 and CA3 regions, evidence suggests that these regions show different vulnerabilities to cell death depending on the stressor. ${ }^{2}$ For example aging-dependent complications, such as cardiovascular disease, ${ }^{3}$ stroke, ${ }^{4}$ and decreased cerebral blood flow ${ }^{5}$ can increase neuronal ischemic damage in the hippocampus. However, area CA1 is the most affected hippocampal region to ischemic insult. ${ }^{6}$ Numerous in vivo studies using rodent models of hippocampal acute/severe ischemia, ${ }^{7}$ or chronic/ mild hypoperfusion, ${ }^{8}$ showed targeted damage to the area CA1, while sparing area CA3.

In addition to ischemic insult, differences in hippocampal vulnerability to stressor-induced damage are observed in debilitating age-dependent diseases, such as Alzheimer's disease. Studies on the human brain show that area CA1 of the hippocampus is one of the earliest brain regions to develop the pathological markers associated with Alzheimer's disease, ${ }^{9}$ and the rodent models have correlated disease pathology to CA1 neuronal loss. ${ }^{10}$ Understanding what mediates regional differences in hippocampal vulnerability may provide novel solutions for treating aging-dependent decline in hippocampal function caused by decreased neuronal health and survival.
Regional differences in hippocampal vulnerability might result from intrinsic CA1/CA3 differences in the regulation of cell-survival pathways. The phosphoinositide kinase-3 pathway, through the activation of protein kinase $B(A K T)$, is particularly important for neuron survival and has been shown to protect neurons against a vast variety of stressors, including ischemia, ${ }^{11} \beta$-amyloid, ${ }^{12}$ and tau pathology. ${ }^{13}$ As AKT activation can protect neurons against stressors known to increase with aging, we sought to determine whether measures of AKT activity differed between areas CA1 and CA3 of the hippocampus across the lifespan.

\section{Results}

Nuclear active AKT differs between CA3 and CA1 regions. Accumulation of nuclear phosphorylated AKT (pAKT) is critical to AKT's antiapoptotic effects. To determine regional hippocampal differences in both nuclear $\mathrm{pAKT}$ levels and regulators of pAKT, nuclear and cytoplasmicenriched fractions were prepared from CA1 and CA3 hippocampal homogenates and used for western blot analysis. Cytoplasmic and nuclear fractions were probed for the nuclear protein, TATA box binding protein (TBP), to verify separation. As expected, TBP was observed primarily in the nuclear protein enriched fractions (Figure 1a) and served as a nuclear loading control in subsequent analyses. Nuclear CA1 and CA3 samples were then probed for AKT phosphorylated at Ser473 (pAKT473, 60 kDa; Figure 1b),

${ }^{1}$ Department of Neuroscience, McKnight Brain Institute, University of Florida, Gainesville, FL, USA

*Corresponding author: TC Foster, Department of Neuroscience, McKnight Brain Institute, University of Florida, PO Box 100244, Gainesville, FL 32610-0244, USA. Tel: 352392 4359; Fax: 352846 0185; E-mail: foster@mbi.ufl.edu

Keywords: hippocampus; PHLPP1; aging; AKT; FOXO3a

Abbreviations: AKT, Protein Kinase B; FOXO3a, Forkhead Box O3a Transcription Factor; CA3, Ammon's horn (area CA3); CA1, Ammon's horn (area CA1); TBP, Tata Box Binding Protein; PTEN, Phosphatase and Tensin Homolog; IGF-1, Insulin-like Growth Factor 1; PP2A-A, Protein phosphatase 2A, subunit A; PHLPP1, PH Domain and Leucine-Rich Repeat Protein Phosphatase 1; PKC, Protein Kinase C; PI3K, Phosphoinositide Kinase-3

Received 01.8.08; revised 02.10.08; accepted 21.10.08; Edited by N Bazan; published online 28.11.08 
d
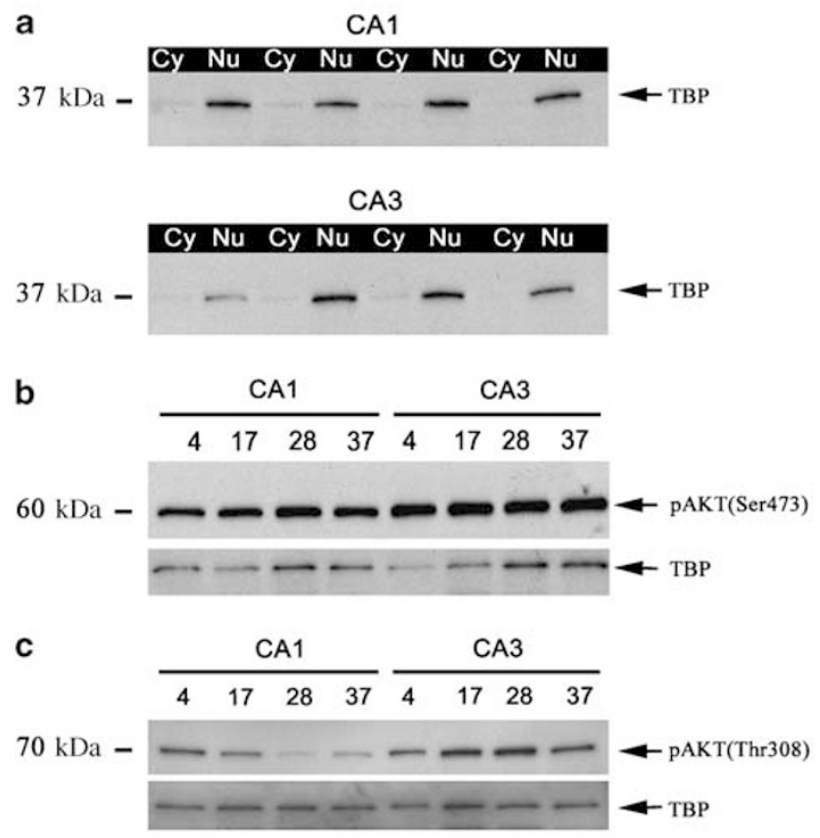

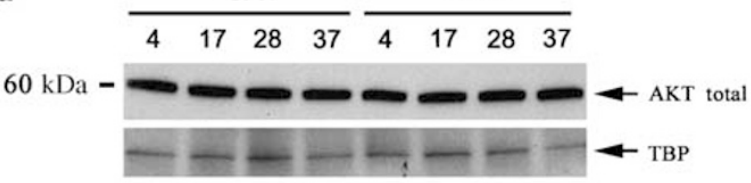

e
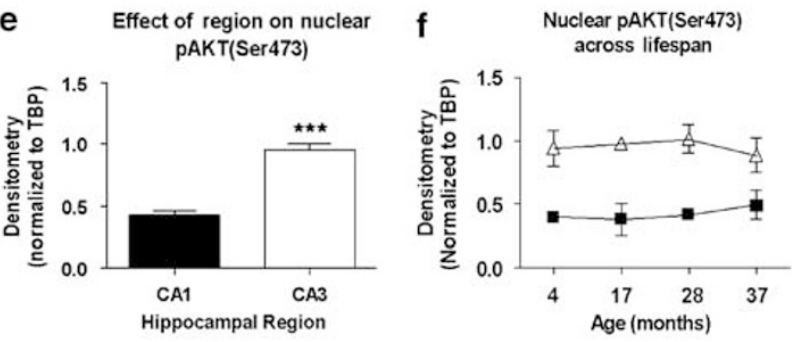

g

Effect of region on nuclear pAKT(Thr308)

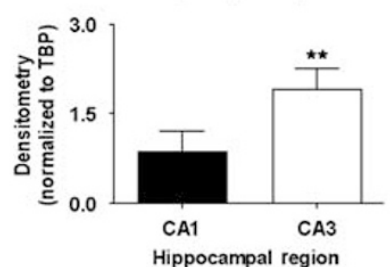

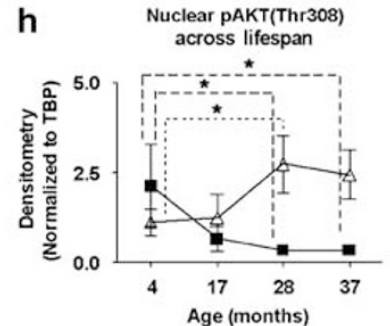

Figure 1 Activated AKT is increased in nuclear fractions from region CA3 compared with region CA1. (a) Control blot showing TBP is localized to nuclear enriched fractions (Nu) relative to cytoplasmic enriched fractions (Cy). (b-d) Representative blots of nuclear CA1/CA3 pAKT473, pAKT308, and total AKT, from animals aged 4, 17, 28, and 37 months (top blots) and TBP nuclear loading control (bottom blots). (e and $\mathbf{g}$ ) Mean nuclear pAKT averaged across ages $(n=15)$ for CA1 (filled bars) and CA3 (open bars). ( $f$ and $h)$ Effect of age on nuclear pAKT in area CA1 (filled squares) and CA3 (open triangles) for animals aged $4(n=4), 17(n=3), 28(n=4)$, and $37(n=4)$ months. Dashed lines indicate significant aging effects in CA1 (---) and CA3 $(\cdots \cdots)$. In this figure and subsequent figures, asterisks indicate significant differences ${ }^{*} P<0.05$, ${ }^{* \star} P<0.01,{ }^{* \star \star} P<0.0001$

AKT phosphorylated at Thr308 (pAKT308, $\sim 75 \mathrm{kDa}$; Figure 1c), and total AKT (Figure 1d). No regional or aging differences were observed in nuclear total AKT levels. In marked contrast, both pAKT473 and pAKT308 were significantly higher in nuclear samples from CA3 when compared with CA1 (Figure 1e and g). Further, although age had no effect on nuclear PAKT473 in either of the regions (Figure 1f), pAKT308 levels were reduced in area CA1 and increased in area CA3 of older animals (Figure $1 \mathrm{~h}$ ). Altogether, the data show regional differences in pAKT with higher levels in area CA3.

Regional differences in hippocampal nuclear FOXO3a. Activated AKT selectively phosphorylates the pro-apoptotic transcription factor forkhead box O3a (FOXO3a) at Ser253, ${ }^{14}$ leading to nuclear exclusion and enhanced cell survival of hippocampal neurons. ${ }^{15}$ Consistent with the decrease in activated AKT in the nuclei of area CA1, immunofluorescent staining of hippocampal sections from a 28-month-old animal indicated lower pFOXO3a253 (red), in nuclei (blue), in area CA1 (Figure 2a-c) relative to CA3 region (Figure 2d-f). Moreover, cells that were negative for the neuronal marker tubulin III (green) exhibited little or no nuclear pFOXO3a253. To determine whether the increase in pFOXO3a253 was associated with lower nuclear FOXO3a levels, hippocampal sections were stained for $\mathrm{FOXO} 3 \mathrm{a}$ (red). Again, total $\mathrm{FOXO} 3 a$ was primarily localized to neurons (green), however; more staining was observed in the nuclei (blue) and perinuclear areas from CA1 (Figure $3 a-c$ ) relative to CA3 (Figure 3d-f). To examine total nuclear FOXO3a levels across the lifespan, western blots of nuclear CA1 and CA3 samples were probed with a polyclonal antibody against FOXO3a and a single band was detected at $\sim 70 \mathrm{kDa}$ (Figure $3 \mathrm{~g}$ ). The results confirmed the FOXO3a immunofluorescence, exhibiting significantly higher levels of total FOXO3a in CA1 compared with CA3, consistent with the ability of pAKT to exclude FOXO3a from the nucleus (Figure 3h). No significant aging effects on nuclear FOXO3a were observed (Figure 3i).

Cytoplasmic factors contributing to regional differences in nuclear PAKT. Activation of AKT in the cytoplasm promotes nuclear PAKT translocation. To determine whether cytoplasmic PAKT showed similar regional differences compared with nuclear pAKT, cytoplasmic samples were probed for pAKT473 (Figure 4a), pAKT308 (Figure 4b), and total AKT (Figure 4c). No significant regional differences were observed for cytoplasmic AKT total or pAKT308. Only cytoplasmic pAKT473 showed significant regional differences (Figure $4 \mathrm{~d}$ and $\mathrm{e}$ ), and was higher in the CA3 compared with CA1. No age-dependent changes were observed for either pAKT473 or pAKT308 (Figure $4 f$ and g). Next we sought to determine if known regulators of cytoplasmic pAKT might show regional hippocampal differences; suggesting a mechanism for increased cytoplasmic CA3 pAKT levels. 

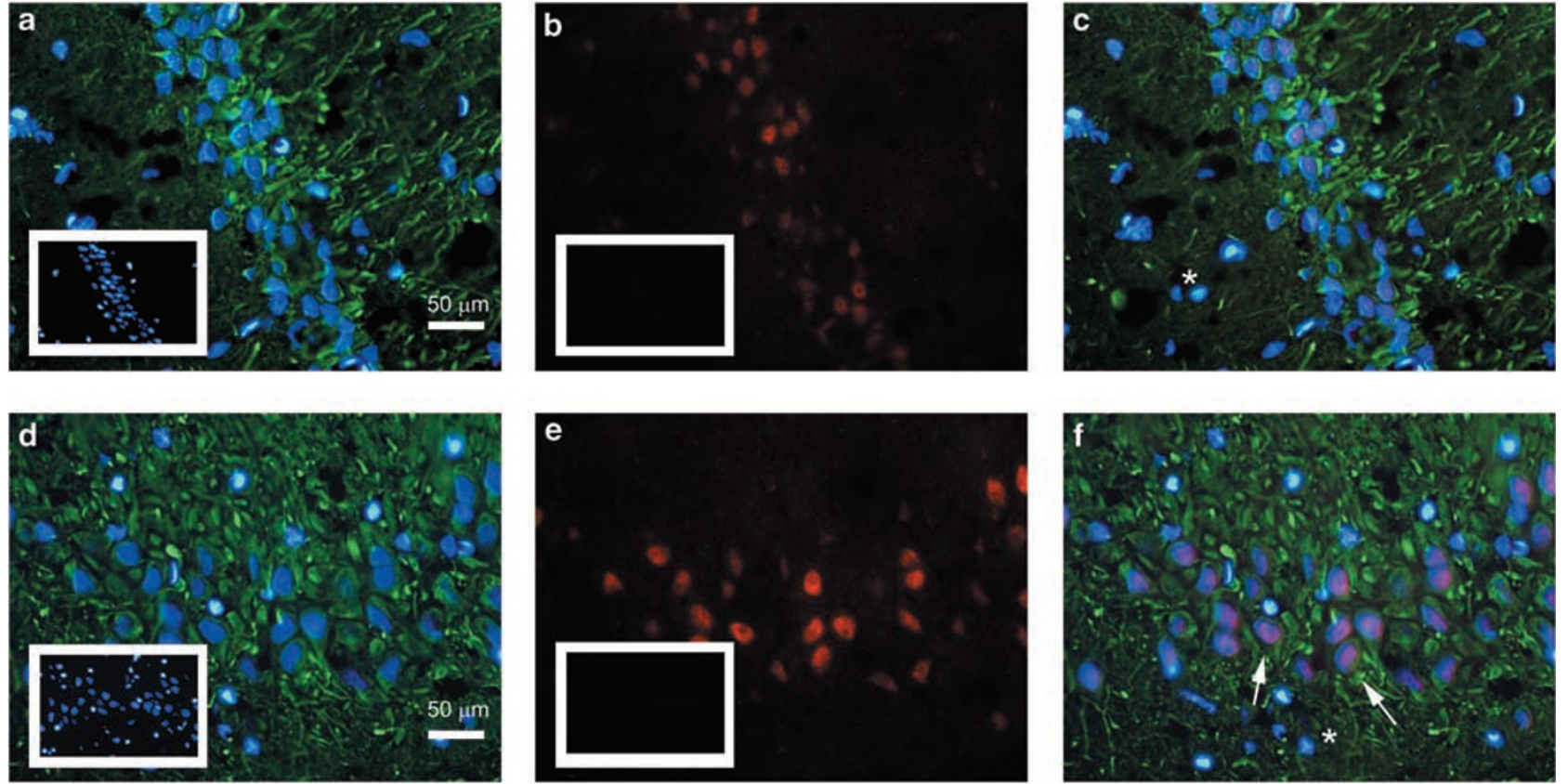

Figure 2 Nuclear pFOXO3a253 is higher in region CA3 and lower in region CA1. (a and d) Immunofluorescence showing CA1 and CA3 neuronal marker tubulin III (green), and nuclei (blue). White boxes in the lower left indicate secondary antibody-only controls. No green staining was observed. (b and $\mathbf{e})$ Immunofluorescence showing $\mathrm{CA} 1$ and $\mathrm{CA} 3$ pFOXO3a253 (red). More staining is observed in region CA3 compared with CA1. No staining was observed in the secondary antibody-only controls. (c and f) Merged images of panels $\mathbf{a} / \mathbf{b}$ and $\mathbf{d} / \mathbf{e}$ showing pFOXO3a. pFOXO3a is localized to the nuclei of CA1 and CA3 pyramidal neurons. White arrows indicate intense nuclear pFOXO3a253 CA3 staining. White asterisks indicate non-neuronal nuclei

The insulin-like growth factor 1 (IGF-1) receptor tyrosine kinase is a robust activator of AKT signaling in hippocampal neurons. Cytoplasmic activation of PI3 kinase by IGF-1 promotes AKT phosphorylation and enhances its nuclear translocation. $^{16}$ To investigate whether expression of IGF-1 receptors contributes to the differential activation of $A K T$, cytoplasmic CA1 and CA3 samples were probed for IGF-1R $\alpha$, and a band was detected at $\sim 150 \mathrm{kDa}$ (Figure $5 \mathrm{a}$ ). No region or age differences in IGF-1R $\alpha$ were observed suggesting that the total receptor expression does not underlie regional differences in cytoplasmic pAKT (Figure 5c).

Next, we investigated whether the activity of IGF-1 receptors might reflect regional differences in pAKT. Activation of IGF-1 receptors requires ligand-dependent autophosphorylation of the IGF-1R $\beta(95 \mathrm{kDa})$ subunit. CA1 and CA3 cytoplasmic samples were probed for phosphorylated IGF$1 \mathrm{R} \beta$ (Tyr1135/1136) and a dominant band was detected at $\sim 95 \mathrm{kDa}$ (Figure $5 \mathrm{~b}$ ). The existence of multiple bands above $95 \mathrm{kDa}$ may be because of additional post-transcriptional modification of IGF-1R $\beta$. Although no significant regional differences in pIGF-1R $\beta$ were observed, there was a significant interaction $(P=0.016)$ between region and aging (Figure 5d). Activated IGF-1 receptors remained stable across the lifespan in CA1. However in CA3, activated IGF-1 receptors were much higher compared with $\mathrm{CA} 1$ in young animals and decreased significantly across the lifespan, falling well below CA1 levels at 37 months of age.

Phosphatase and tensin homolog (PTEN) can act as a negative regulator of AKT at the cell membrane. ${ }^{17}$ Total cytoplasmic PTEN was detected as a single band at $\sim 50 \mathrm{kDa}$ and levels were not different across regions (Figure 6a). In contrast, PTEN levels varied as a function of age $(P<0.001)$ with the highest levels observed between 17 and 28 months (Figure 6c). PTEN is regulated by multiple phosphorylation sites, including Ser370 such that the phosphorylated form (pPTEN370) is less active than the dephosphorylated form. Therefore, cytoplasmic samples were probed with an antibody specific for PPTEN370, and a band was detected at $\sim 55 \mathrm{kDa}$ (Figure 6b). The level of pPTEN370 was not influenced by age, (Figure 6d) however, pPTEN370 was significantly higher in cytoplasmic CA1 samples relative to region CA3 (Figure 6e). As pPTEN370 should enhance the level of pAKT, the activity of PTEN does not seem to explain the reduced level of nuclear $\mathrm{pAKT}$ in region $\mathrm{CA} 1$.

\section{Phosphatases directly acting on AKT contribute to} regional differences in nuclear PAKT. The serine/ threonine phosphatase protein phosphatase 2A (PP2A) turns off AKT activity by dephosphorylation of AKT at Thr308. ${ }^{18}$ CA1 and CA3 nuclear fractions were probed with an antibody against the PP2A-A subunit, and a single band was detected at $\sim 60 \mathrm{kDa}$ (Figure $7 \mathrm{a}$ ). Comparing CA1 and CA3 hippocampi across age groups showed no significant regional or age differences in total PP2A-A, suggesting that nuclear PP2A-A levels do not underlie the robust regional differences in active AKT (Figure 7c).

The $\mathrm{PH}$ domain and leucine-rich repeat protein phosphatase 1 (PHLPP1) dephosphorylates AKT at Ser473 in a highly specific fashion. ${ }^{19}$ Examination of nuclear fractions for total PHLPP1 (Figure 7b) indicated that PHLPP1 tended $(P=0.096)$ to increase with age from 17 months to 38 months (Figure 7d). Furthermore, significantly higher levels of 

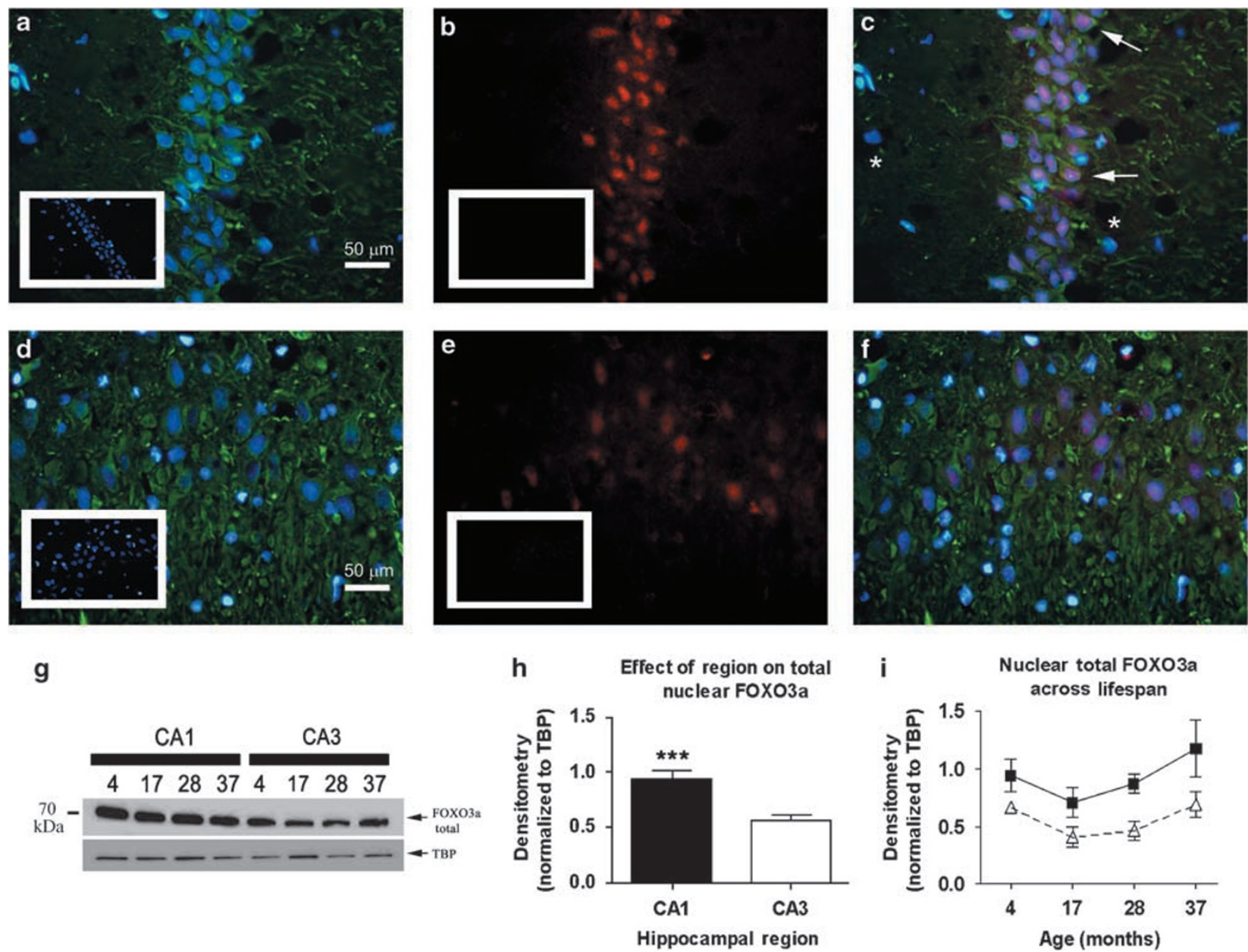

Figure 3 Nuclear total FOXO3a is lower in region CA3 and higher in region CA1. (a and d) Immunofluorescence showing CA1 and CA3 neuronal marker tubulin III (green), and nuclei (blue). White boxes in the lower left indicate secondary antibody-only controls. No green staining was observed. (b and $\mathbf{e})$ Immunofluorescence showing CA1 and CA3 total FOXO3a (red). More staining is observed in region CA1 compared with CA3. No staining was observed in the secondary antibody-only controls. (c and f) Merged images of panels $\mathbf{a} / \mathbf{b}$ and $\mathbf{d} / \mathbf{e}$ showing total FOXO3a. FOXO3a is localized to the nuclei and perinuclear areas of CA1 and CA3 pyramidal neurons. White arrows indicate intense nuclear total FOXO3a CA1 staining. White asterisks indicate non-neuronal nuclei. (g) Representative blot showing nuclear CA1/CA3 total FOXO3a (top blot) and TBP (bottom blot) from animals aged 4, 17, 28, and 37 months. (h) Mean normalized density averaged across ages $(n=15)$ in CA1 (filled bars) and CA3 (open bars). (i) Nuclear FOXO3a plotted as a function of age for CA1 (filled squares) and CA3 (open triangles), for animals aged $4(n=4), 17(n=3), 28(n=4)$, and 37 ( $n=4)$ months

PHLPP1 were observed in CA1 nuclear samples compared with CA3 (Figure 7e). Consistent with recent reports that PHLPP1 dephosphorylates PAKT473, the variability in the level of nuclear pAKT473 in CA1 and CA3 regions across the lifespan was negatively correlated with levels of nuclear PHLPP1 $(P<0.001)$ (Figure 7f). In agreement with western blot analysis, immunofluorescent staining from a 28-monthold animal indicated more CA1 PHLPP1 (red) compared with area CA3 (Figure $7 \mathrm{~g}$ and $\mathrm{h}$ ). To verify antibody specificity, nuclear enriched fractions were probed with the same PHLPP1 antibody used for immunofluorescence, and a single dominant band was observed at approximately $145 \mathrm{kDa}$ (Supplementary Figure 1).

Cytoplasmic pAKT473 was reduced in CA1 across the lifespan, and immunofluorescence showed higher cytoplasmic CA1 PHLPP1 (in addition to nuclear CA1 PHLPP1). Therefore, we examined whether cytoplasmic PHLPP1 levels were higher in area CA1 across lifespan (Figure 8a).
Collapsed across ages, cytoplasmic CA1 PHLPP1 was significantly higher compared with CA3 (Figure 8b). However, there was a significant interaction $(P=0.036)$ between aging and region. Though CA3 cytoplasmic PHLPP1 remained low across the lifespan, CA1 PHLPP1 showed more variation; significantly dropping from 4 to 17 months of age, and significantly rising from 17 to 28 months of age (Figure 8c).

To support our conclusion that PHLPP1 contributes to the regional differences in hippocampal nuclear PAKT across lifespan, we were interested in probing an additional signaling protein known to be dephosphorylated by PHLPP1, but independent from the AKT pathway. Recently, Gao et al. $(2008)^{20}$ showed that knockdown of PHLPP increased phosphorylation of protein kinase $\mathrm{C} \alpha(\mathrm{PKC} \alpha)$ in vitro. Therefore, we probed for regional nuclear differences in total PKC $\alpha$ (Figure 9a) and PKC $\alpha$ phosphorylated at Ser 657 (pPKC $\alpha 657$; Figure 9b). Both showed a prominent band at $\sim 75 \mathrm{kDa}$. No change in nuclear total PKC $\alpha$ was observed for region or age. 


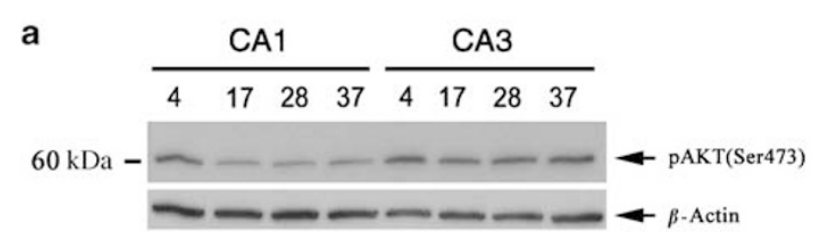

b

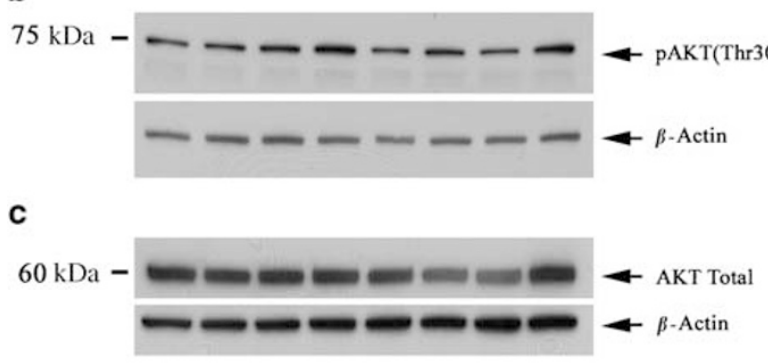

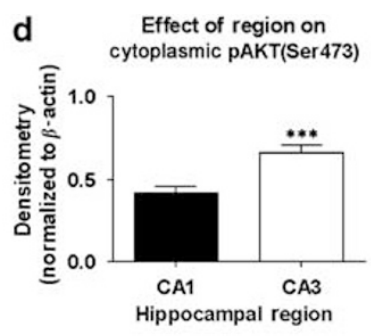

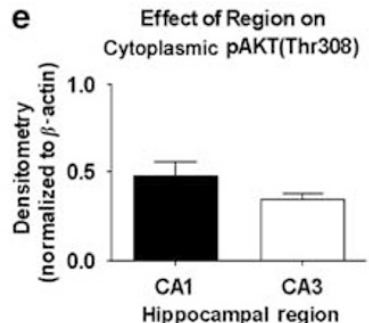

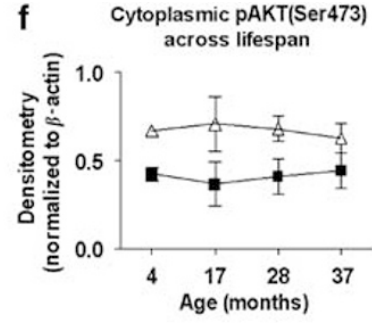

g Cytoplasmic pAKT(Thr308) across lifespan

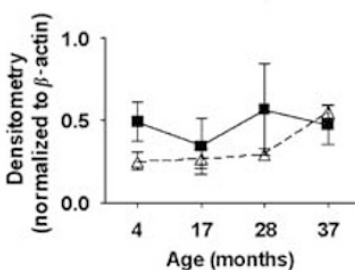

Figure 4 Only AKT phosphorylated at Ser473 is increased in cytoplasmic fractions from region CA3 compared with region CA1. (a-c) Representative blots of cytoplasmic CA1/CA3 pAKT473, pAKT308, and total AKT, from animals aged 4, 17, 28, and 37 months (top blots) and $\beta$-actin cytoplasmic loading control (bottom blots). (d and e) Mean cytoplasmic pAKT averaged across ages for CA1 ( $n=14$; filled bars) and CA3 ( $n=15$; open bars). ( $f$ and $\mathbf{g}$ ) No effect of age on cytoplasmic pAKT in area CA1 (filled squares) and CA3 (open triangles) for animals aged $4(n=4), 17(n=3), 28(n=4)$, and 37 (CA1 $n=3 / \mathrm{CA} 3 n=4)$ months

However, pPKC $\alpha 657$ was significantly higher in area CA3 consistent with our observations that PHLPP1 was lower in this region (Figure 9c). No effect of age was observed for pPKC $\alpha 657$ (Figure 9d).

\section{Discussion}

Regional differences in AKT survival signaling. The main finding of this study was an increase in the activity of the AKT pathway in CA3 relative to CA1. AKT is activated by phosphorylation at Thr308 and Ser473 and we observed increased levels of PAKT in region CA3 in the absence of regional differences in total AKT expression. Nuclear pAKT473 was approximately $50 \%$ higher in area CA3 compared with CA1, and cytoplasmic pAKT473 was approximately $25 \%$ higher in area CA3 compared with cytoplasmic CA1. Further, nuclear pAKT308 was increased in area CA3. In addition, regional differences in the AKT nuclear target substrate, FOXO3a, were consistent with differences in the level of PAKT. FOXO proteins have been shown to play a pro-apoptotic role in the hippocampus, and are activated under ischemic conditions. ${ }^{21}$ AKT negatively regulates the pro-apoptotic protein $\mathrm{FOXO} a$ through the shuttling and degradation of $\mathrm{FOXO} 3 \mathrm{a}^{22}$ This regulation involves AKT-mediated phosphorylation of FOXO3a at Ser253, ${ }^{23}$ and the level of pFOXO3a253 provides a measure of AKT activity. Examinations of pFOXO3a253 with immunofluorescence indicated increased phosphorylation in region $\mathrm{CA} 3$, confirming that AKT signaling is particularly high within the nuclei of $\mathrm{CA} 3$ pyramidal neurons. The phosphorylation of $\mathrm{FOXO} a$ is the primary step in translocation of $\mathrm{FOXO} 3 a$ out of the nucleus for degradation in the cytoplasm. ${ }^{24}$ Thus, despite the increase in pFOXO3a253, total FOXO3a was significantly reduced in nuclear fractions from hippocampal CA3 compared with CA1.
The results on PAKT and FOXO3a are consistent with the increase in the level of AKT activity in region CA3 and suggest that the differential regional vulnerability is related to decreased AKT signaling in region CA1.

In addition to AKT/FOXO3a protein levels, robust regional differences were observed for phosphorylated PKC $\alpha$. Studies suggest that activated PKC $\alpha$ can also play an important role in cell survival and growth. ${ }^{25}$ Moreover, marked down regulation of $\mathrm{PKC} \alpha$ and other PKC isoforms in the vulnerable CA1 hippocampal region has been observed after hippocampal ischemic injury. ${ }^{26}$ Down regulation of $\mathrm{PKC} \alpha$ after ischemia was not seen in damage-resistant hippocampal regions. Therefore, the increase of phosphorylated nuclear PKC $\alpha$ in region CA3 may also help to protect against ischemic damage across the lifespan.

Regulation of AKT survival signaling. We were interested in determining whether differences in AKT regulators might help to show the mechanism responsible for regional differences in hippocampal nuclear pAKT. The IGF-1/PI3 kinase pathway is a classic activator of AKT. IGF-1 binding to the IGF- $1 \alpha$ receptor subunit leads to autophosphorylation/ activation of IGF-1R $\beta$ receptor subunit, and downstream phosphorylation of AKT. It has been reported that IGF-1 receptor levels are higher in CA3 relative to CA1 in young and old animals. ${ }^{27}$ Therefore, we expected to see higher levels of CA3 IGF-1R $\alpha$ expression across the lifespan. However, we found no regional variation in IGF-1R $\alpha$ total, suggesting IGF-1 receptor levels are not responsible for robust increase in CA3 pAKT. Differences in our results may be explained by the aforementioned study using radioligandbinding assays, in which IGF-1 ligand was used as the probe to evaluate receptor totals. As the brain and hippocampus express IGF-1 binding proteins and receptors, studies using IGF-1 binding do not differentiate the IGF-1 receptor from IGF-1 binding proteins. 
a

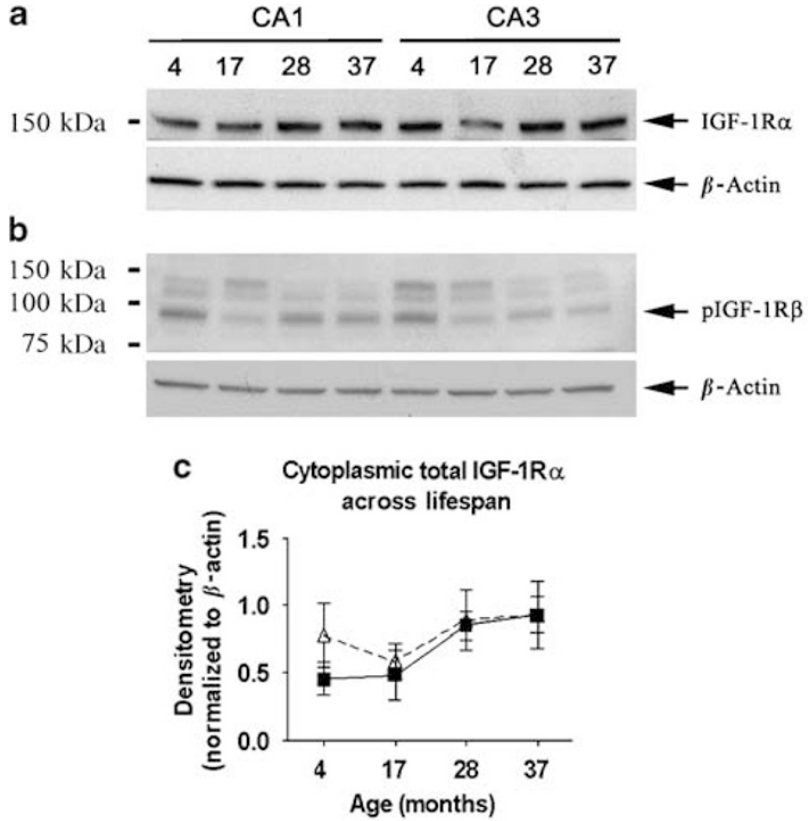

d Cytoplasmic pIGF-1R $\beta$ across lifespan

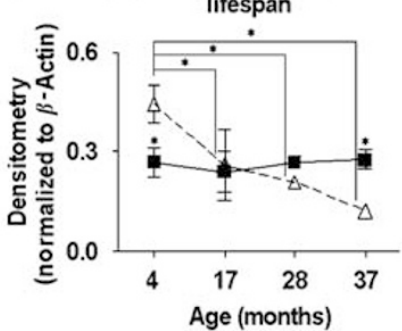

Figure 5 IGF-1 receptors do not predict regional differences in pAKT. (a and $\mathbf{b}$ ) Representative blots showing total cytoplasmic IGF-1R $\alpha$ and cytoplasmic pIGF-1R $\beta$ from animals aged $4,17,28$, and 37 months (top blots) and cytoplasmic loading control $\beta$-actin (bottom blots). (c) No effect of age or region for cytoplasmic IGF-1R $\alpha$ in area CA1 (filled squares) and CA3 (open triangles) in animals aged $4(n=4), 17$ $(n=3), 28(n=4)$, and $37(n=4)$ months. (d) No effect of age for cytoplasmic plGF-1R $\beta$ in area CA1 (filled squares). However, there is a significant agedependent decline in area CA3 (open triangles) for animals aged $4(n=4), 17$ $(n=3), 28(n=4)$, and $37(n=4)$ months. Solid lines indicate aging differences in CA3 PIGF-1R $\beta$

We next determined whether regional differences in IGF-1 receptor activity, as measured by IGF-1R $\beta$ phosphorylation, might explain regional differences in pAKT. Intriguingly, though no change in CA1 IGF-1R $\beta$ phosphorylation was observed, there was an age-dependent decline in CA3 IGF1R $\beta$ phosphorylation. However, decreased CA3 IGF-1R $\beta$ phosphorylation did not reflect differences in either CA3 pAKT473 or pAKT308 levels. The data suggest that (1) IGF-1 does not mediate the observed increase in CA3 PAKT levels, and (2) aging differentially impacts CA1 and CA3 IGF-1 receptor activity. In support for this conclusion, earlier studies in old rats showed that intraventricular perfusion of IGF-1 failed to correct an age-dependent reduction in glucose metabolism in area $\mathrm{CA} 3$, however, it did improve glucose metabolism in area CA1. ${ }^{28}$
The phosphatases PTEN and PP2A also regulate PAKT levels. PTEN works upstream to prevent AKT activation in the cytoplasm, whereas PP2A works downstream to dephosphorylate nuclear pAKT. However, no regional differences in cytoplasmic PTEN or nuclear PP2A were observed. Unexpectedly, phosphorylated (i.e. inhibited) PTEN was increased in cytoplasmic samples from region CA1. Initial findings suggest that PTEN and PP2A do not mediate the observed regional differences in nuclear PAKT across the lifespan. Nevertheless, it should be noted that many additional post-transcriptional modifications can alter phosphatase activity of PTEN ${ }^{29}$ and PP2A. ${ }^{30}$ As we did not measure phosphatase activity directly, the potential contribution of PTEN and PP2A activity to PAKT levels cannot be addressed by these experiments. The role of phosphatase activity deserves future investigation; particularly because PTEN and PP2A play a direct role in the regulation of PAKT308.

In contrast to PTEN and PP2A, regional differences were observed for the expression of the phosphatase PHLPP1. Current knowledge of how PHLPP phosphatase activity is regulated remains limited. PHLPP exists as two isoforms, PHLPP1 and PHLPP2, of which the first isoform has two splicoforms, PHLPP1 $\alpha \quad(\sim 135 \mathrm{kDa})$ and PHLPP1 $\beta$ $(\sim 190 \mathrm{kDa}) .{ }^{31}$ Studies by Gao et al. $(2005)^{19}$ showed that PHLPP $1 \alpha$ directly binds and dephosphorylates PAKT at Ser473. These researchers found that knockdown of PHLPP1 in 293T cells caused an upregulation of endogenous phosphorylated PKC $\alpha$. To date, no phosphorylation sites or other post-transcriptional modifications of PHLPP1 have been discovered, though they likely exist. However, Shimizu et al. $(2007)^{32}$ showed calpain-mediated cleavage of PHLPP could downregulate phosphatase activity on target substrates in area CA1 of the hippocampus, and prevent nuclear activation of MAPK/CREB. These results suggest that proteolytic degradation of PHLPP1 is an important regulatory mechanism of phosphatase activity.

Our results are consistent with the idea that changes in total hippocampal PHLPP1 levels are important in regulating the degree of PAKT473 phosphorylation. Thus, hippocampal nuclear PHLPP1 levels matched regional differences in nuclear PAKT473 such that PHLPP1 was elevated in region CA1, and CA1 exhibited the lowest level of nuclear pAKT473. Furthermore, nuclear PHLPP1 levels were inversely correlated with pAKT473 levels across the lifespan. Finally, the observed decrease in CA1 nuclear pPKC $\alpha 657$, another substrate for PHLPP1, supported our conclusion that the level of nuclear PHLPP1 is important in the regulation of target nuclear substrates.

In addition to nuclear PHLPP1, cytoplasmic levels of PHLPP1 were reduced across the lifespan in area CA3 and cytoplasmic PAKT473 levels were higher across the lifespan in area CA3. Alternatively, cytoplasmic PHLPP1 collapsed across age, was significantly higher in region CA1. Altogether, the nuclear and cytoplasmic data suggest that cellular levels of PHLPP1 are higher in CA1 region and correspond to reduced cellular levels of PAKT473. It is noted that, regional differences in cytoplasmic pAKT308 were not observed. These findings support our conclusion that PHLPP1 is important in selectively regulating pAKT473 levels across the lifespan, and suggest that regional differences in nuclear 
a

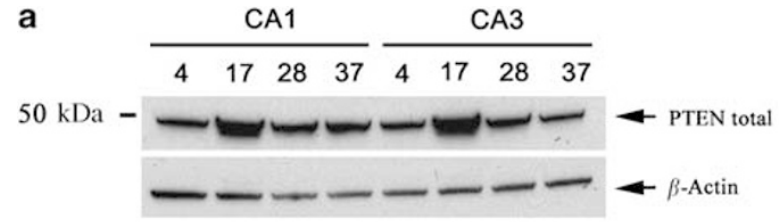

C

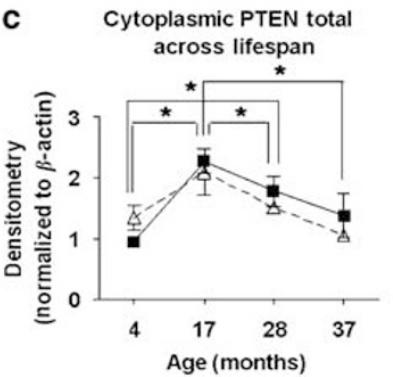

d

Cytoplasmic pPTEN(Ser370) across lifespan

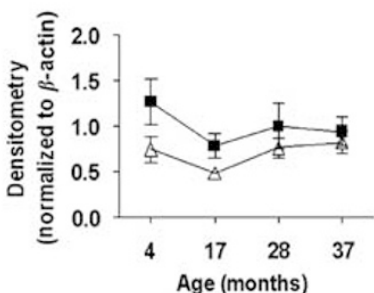

b

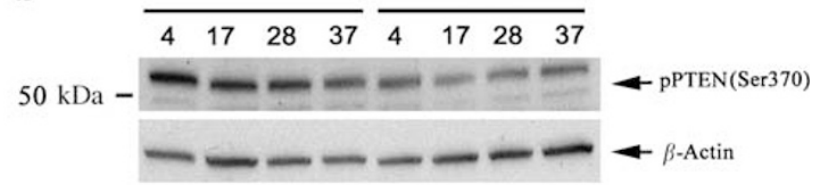

e Effect of region on cytoplasmic PPTEN(Ser370)

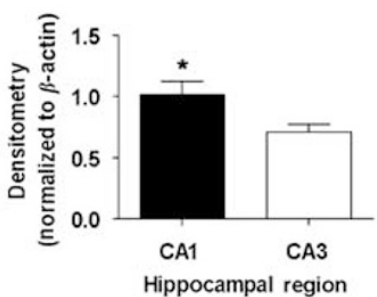

Figure 6 PTEN does not predict regional differences in pAKT. (a and $\mathbf{b})$ Representative blots showing total PTEN, and pPTEN370 in animals aged 4, 17, 28, and 37 months (top blots) and cytoplasmic loading control $\beta$-actin (bottom blots). (c) CA1 (filled squares) and CA3 (open triangles) cytoplasmic total PTEN shows no significant regional effects but significant aging effects in animals aged $4(n=4), 17(n=3), 28(n=4)$, and $37(n=4)$ months. Solid lines indicate aging differences in CA1/CA3 total PTEN . (d) CA1 (filled squares) and CA3 (open triangles) cytoplasmic pPTENSer370 was not different across the lifespan in animals aged $4(n=4), 17(n=3), 28(n=4)$, and $37(n=4)$ months, however, (e) elevated levels of pPTEN370 were observed $(n=15)$ in region CA1 (filled bars) relative to CA3 (open bars)

CA1/CA3 pAKT308 depend upon regulation (or dysregulation) by mechanisms distinct from PHLPP1.

Despite our data supporting PHLPP1's role in mediating regional differences in hippocampal pAKT473, additional regulation seems very likely; primarily because CA1 pAKT473 levels were remarkably stable across the lifespan in both the nucleus and the cytoplasm whereas CA1 PHLPP1 showed much more variability. One possibility is that regional differences in growth factor-mediated AKT activation, other than IGF-1, help to regulate AKT across the lifespan. Immunohistochemical studies in rat brain showed that BDNF levels are extremely high in area CA3 and extremely low in area $\mathrm{CA} 1 .{ }^{33}$ Further, these differences are maintained across the lifespan. ${ }^{34}$ As BDNF can activate AKT, and has been shown to rapidly inhibit FOXO3a nuclear localization, ${ }^{35}$ BDNF signaling may also contribute to the observed maintenance of pAKT across the lifespan. However, comparative studies of growth factor-mediated survival signaling in hippocampal cell culture show that IGF-1 strongly induces AKT although it weakly induces ERK, whereas BDNF strongly induces ERK and only weakly induces AKT. ${ }^{36}$ Therefore, whether BDNF contributes to sustained AKT activity in vivo and whether its contribution is large or small remains unknown and deserves further investigation.

AKT activity across the lifespan. Aging-dependent dysregulation of proteins that mediate survival signaling may contribute to increased hippocampal vulnerability during aging. The results of this study indicate that the level of nuclear pAKT308 declines in CA1 region as age advances. Alternatively, CA1 pAKT473 was stable across the lifespan. This raises the question of whether the loss in dual pAKT exacerbates vulnerability of CA1 region as age advances. Recent in vitro studies examining the regulation of AKT phosphorylation and AKT activity provided evidence that dual phosphorylation of pAKT308 and pAKT473 are temporally associated/coordinated, and together predicted AKT activity. ${ }^{37}$ In addition, studies in NIH3T3 cells showed that a pAKT308 mutant failed to activate when treated with growth factor, whereas a pAKT473 mutant showed reduced activity; thus dual phosphorylation seems to be required for full AKT kinase activity. ${ }^{38}$ In aged animals, decreased CA1 pAKT308 levels would predict reduced total AKT activity even though pAKT473 remained stable.

It is unclear what mechanism(s) underlie the age-related decline in nuclear CA1 pAKT308. One possible explanation may be that aging differentially affects nuclear CA1/CA3 membrane phosphatidylinositol $(3,4,5)$-trisphosphate $\left(\mathrm{PIP}_{3}\right)$ levels. AKT can be activated in the nucleus by identical signaling mechanisms observed at the cell membrane. ${ }^{39}$ However, before AKT can be phosphorylated at Thr308, PI3 kinase must be activated upstream. When activated, PI3 kinase will phosphorylate membrane bound $\mathrm{PIP}_{2}$ to $\mathrm{PIP}_{3}$. $\mathrm{PIP}_{3}$ will then allow both $\mathrm{AKT}$ and $\mathrm{PIP}_{3}$-dependent kinase 1 (PDK1) to bind the inner membrane through their $\mathrm{PH}$ domains. PDK-1 is responsible for phosphorylating AKT at Thr308, and binding of both enzymes to $\mathrm{PIP}_{3}$ is critical to allowing PDK-1 access to AKT's active site at Thr308. Therefore, changes in the nuclear $\mathrm{CA} 1 \mathrm{PIP}_{3}$ levels across the lifespan could alter the nuclear CA1 AKT308 levels. However, little is known about the regulation and control of nuclear $\mathrm{PIP}_{3}$, let alone how aging might influence nuclear $\mathrm{PIP}_{3}$ levels.

Alternatively, $\mathrm{Ca}^{2+} /$ calmodulin-dependent protein kinase kinase (CaM-KK) can selectively and directly phosphorylate AKT at Thr308 but not on Ser473. ${ }^{40}$ Intriguingly, CaM-KK $\alpha$ is found only in the nucleus, where it acts to regulate its better known substrate $\mathrm{Ca}^{2+}$ /calmodulin-dependent protein kinase IV. As $\mathrm{Ca}^{2+}$ imbalance plays an important role in hippocampal CA1 loss of function with aging, altered hippocampal CaMKK activity with age may also play a role in selectively altering nuclear pAKT308 phosphorylation across the lifespan in area CA1. This idea remains to be tested. 
a

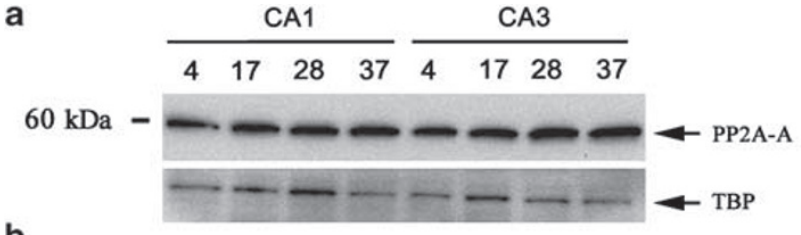

b
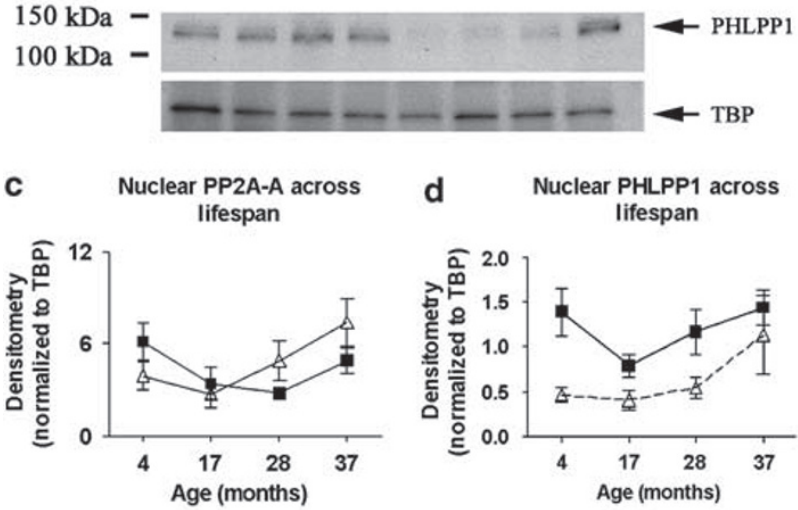

d Nuclear PHLPP1 across
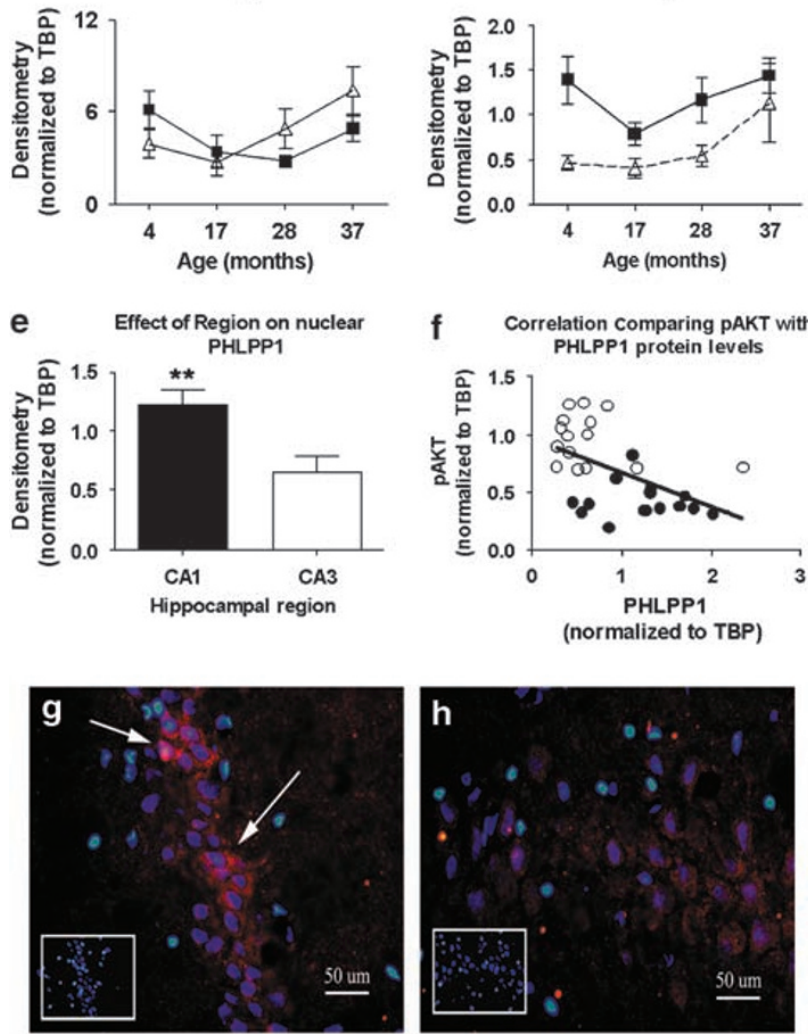

Figure 7 Nuclear PHLPP1 but not PP2A-A correlate with regional differences in nuclear pAKTSer473. (a and $\mathbf{b}$ ) Representative blots showing nuclear total PP2A-A and PHLPP1 in animals aged 4, 17, 28, and 37 months (top blots) and TBP (bottom blots) (c) CA1 (filled squares) and CA3 (open triangles) nuclear PP2A-A across the lifespan. (d) CA1 (filled squares) and CA3 (open triangles) nuclear PHLPP1 had a tendency to increase with age, and (e) significant regional differences $(n=15)$ were observed in CA1 (filled bars) relative to CA3 (open bars). (f) Linear regression of combined CA1 (dark circles)/CA3 (open circles) samples across the lifespan showing PHLPP1 levels correlate with pAKTSer473 $\left(r^{2}=0.27\right)$. (g and $\left.\mathbf{h}\right)$ Immunofluorescence showing CA1 and CA3 PHLPP1 (red) and nuclei stained with DAPI (blue). White border squares in the bottom left indicate secondary antibodyonly controls. White arrow heads indicate nuclear and perinuclear regions of intense PHLPP1 staining in area CA1. Animals aged $4(n=4), 17(n=3), 28(n=4)$, and $37(n=4)$ months were used for lifespan graphs

Altogether, the results suggest that the regional hippocampal differences in the AKT pathway may contribute to regional differences in neuronal vulnerability to certain stressors, and help protect CA3 neurons from pathology associated with age-dependent disease. In support for these conclusions, the
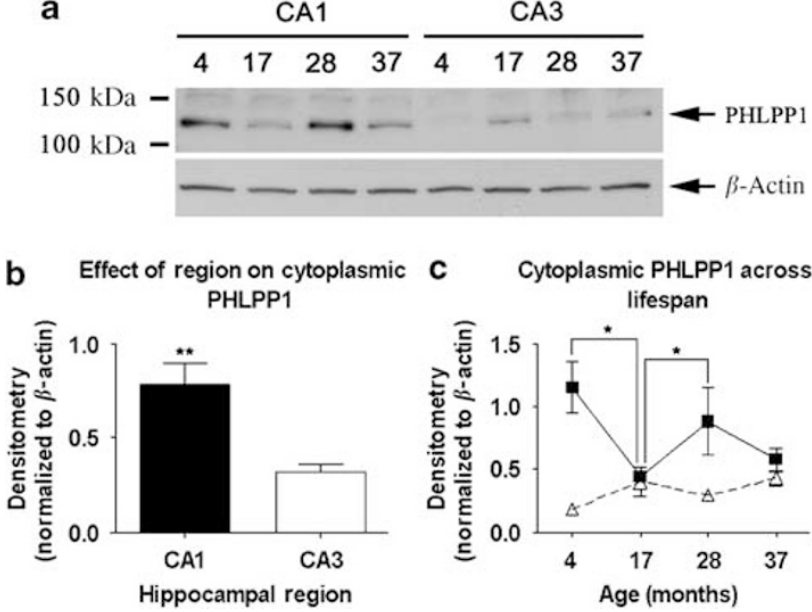

Figure 8 Cytoplasmic PHLPP1 is increased in area CA1. (a) Representative blot showing cytoplasmic total PHLPP1 in animals aged 4, 17, 28, and 37 months (top blot) and $\beta$-actin (bottom blot) (b) Mean normalized densitometry averaged across ages $(n=15)$ in CA1 (filled bars) and CA3 (open bars). Significant regional differences in cytoplasmic PHLPP1 $(n=15)$ were observed in area CA1 (filled bars) relative to area CA3 (open bars). (c) CA1 PHLPP1 show significant variation across the lifespan (filled squares). Solid lines indicate aging differences in CA1 PHLPP1. Alternatively CA3 (open triangles) cytoplasmic PHLPP1 showed reduced and stable levels across the lifespan. Animals aged $4(n=4), 17(n=3), 28(n=4)$, and 37 $(n=4)$ months were used for lifespan graph

a

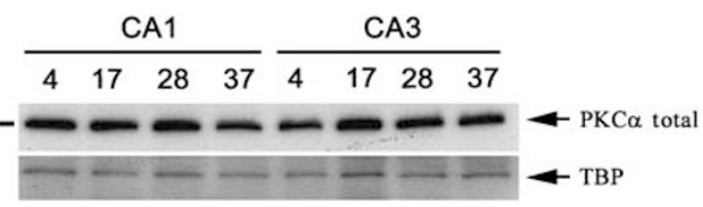

b

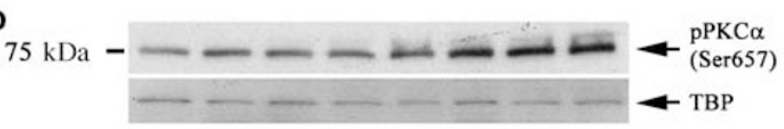

c Effect of region on nuclear d Nuclear pPKC $\alpha$ (Ser657) pPKC $\alpha($ Ser657)
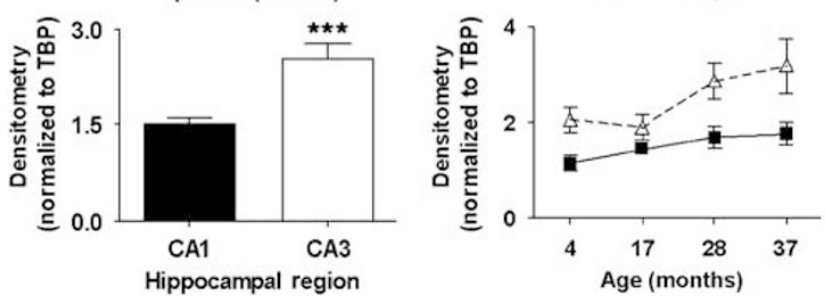

Figure 9 Regional differences in nuclear pPKC $\alpha 657$. (a and $\mathbf{b}$ ) Representative blots showing nuclear $\mathrm{CA} 1 / \mathrm{CA} 3$ total $\mathrm{PKC} \alpha$ and $\mathrm{pPKC} \alpha 657$ levels in animals aged $4,17,28$, and 37 months (top blots) normalized to TBP (bottom blots). (c) Mean normalized densitometry averaged across ages $(n=15)$ in CA1 (filled bars) and CA3 (open bars). Significantly higher levels of pPKC $\alpha 657$ are observed in the nucleus of area CA3. (d) CA1 (filled squares) and CA3 (open triangles) nuclear pPKC $\alpha 657$ shows no significant aging effects. Animals aged $4(n=4), 17(n=3)$, $28(n=4)$, and $37(n=4)$ months were used for lifespan graph

pro-apoptotic protein FOXO3a was higher in area CA1 across lifespan and actively inhibited in pyramidal neuron nuclei of region CA3. Further, nuclear PHLPP1 was higher in CA1 
Table 1 Antibody list

\begin{tabular}{|c|c|c|c|c|}
\hline Antibody & Concentration & Host & Clonality & Company \\
\hline $\begin{array}{l}\text { TBP } \\
\beta \text {-Actin } \\
\text { p(Thr308)AKT } \\
\text { p(Ser473)AKT } \\
\text { AKT total } \\
\text { FOXO3a } \\
\text { pFOXO3a253 (Immuno-Fluo) } \\
\text { FOXO3a (Immuno-Fluo) } \\
\text { IGF-1R } \alpha \\
\text { plGF-1R } \beta \\
\text { p(Ser370)PTEN } \\
\text { PTEN total } \\
\text { PP2A-A } \\
\text { PHLPP1 } \\
\text { PHLPP1 (Immuno-Fluo) } \\
\text { p(Ser657)PKC } \alpha \\
\text { PKC } \alpha \text { total } \\
\text { Neuronal } \beta \text {-tubulin III }\end{array}$ & $\begin{array}{l}1: 1000 \\
1: 8000 \\
1: 1000 \\
1: 1000 \\
1: 1000 \\
1: 1000 \\
2 \mu \mathrm{g} / \mathrm{ml} \\
1: 100 \\
1: 200 \\
1: 1000 \\
1: 1000 \\
1 \mu \mathrm{g} / \mathrm{ml} \\
1: 1000 \\
1: 200 \\
1: 50 \\
0.5 \mu \mathrm{g} / \mathrm{ml} \\
0.4 \mu \mathrm{g} / \mathrm{ml} \\
1: 1000\end{array}$ & $\begin{array}{l}\text { Mouse } \\
\text { Chicken } \\
\text { Rabbit } \\
\text { Rabbit } \\
\text { Rabbit } \\
\text { Rabbit } \\
\text { Rabbit } \\
\text { Rabbit } \\
\text { Rabbit } \\
\text { Rabbit } \\
\text { Rabbit } \\
\text { Rabbit } \\
\text { Mouse } \\
\text { Goat } \\
\text { Rabbit } \\
\text { Rabbit } \\
\text { Mouse } \\
\text { Mouse }\end{array}$ & $\begin{array}{l}\text { Monoclonal } \\
\text { Polyclonal } \\
\text { Monoclonal } \\
\text { Polyclonal } \\
\text { Polyclonal } \\
\text { Polyclonal } \\
\text { Polyclonal } \\
\text { Monoclonal } \\
\text { Polyclonal } \\
\text { Monoclonal } \\
\text { Polyclonal } \\
\text { Polyclonal } \\
\text { Monoclonal } \\
\text { Polyclonal } \\
\text { Polyclonal } \\
\text { Polyclonal } \\
\text { Monoclonal } \\
\text { Monoclonal }\end{array}$ & $\begin{array}{l}\text { ABR } \\
\text { Abcam } \\
\text { Cell signaling } \\
\text { Cell signaling } \\
\text { Cell signaling } \\
\text { ABR } \\
\text { Abcam } \\
\text { Cell signaling } \\
\text { Santa Cruz } \\
\text { Cell signaling } \\
\text { Abcam } \\
\text { Abcam } \\
\text { Cell signaling } \\
\text { Santa Cruz } \\
\text { Cayman } \\
\text { Upstate } \\
\text { Upstate } \\
\text { Abcam }\end{array}$ \\
\hline
\end{tabular}

AKT, protein kinase B; pAKT, phosphorylated AKT; FOXO3a, forkhead box O3a transcription factor; pFOXO3a, phosphorylated FOXO3a; IGF-1, insulin-like growth factor 1; pIGF-1, phosphorylated IGF-1; pPTEN, phosphorylated PTEN; PHLPP1, PH domain and leucine-rich repeat protein phosphatase 1; PKC $\alpha$, protein kinase $\mathrm{C} \alpha ; \operatorname{pPKC} \alpha$, phosphorylated PKC $\alpha$; PTEN, phosphatase and tensin homolog; TBP, TATA box binding protein

region and correlated with levels of nuclear pAKT473. To the best of our knowledge, these findings are novel and suggest a new hypothesis to explain the mechanisms for CA1 vulnerability to certain kinds of stressors.

\section{Materials and Methods}

Aged animals. NIA Fischer 344/Brown Norway rats were kept in specific pathogen free (SPF) housing and maintained on a $12 \mathrm{~h}$ light/dark cycle. Animals were aged $4(n=4), 17(n=3), 28(n=4)$, and $37(n=4)$ months, and fed a standard ad libitum diet. Animals were killed by $\mathrm{CO}_{2}$ asphyxiation and decapitated. Hippocampi were removed, separated into $\mathrm{CA} 1$ and $\mathrm{CA} 3$ sections, and flash frozen in liquid nitrogen. Samples were stored at $-80^{\circ} \mathrm{C}$ until further processing.

Homogenization \& nuclear enrichment. Tissues were homogenized using NER nuclear separation kit (PIERCE) according to the manufacturer's instructions. Briefly, frozen samples ( $\sim 30-40 \mathrm{mg}$ of tissue/sample) were removed from $-80^{\circ} \mathrm{C}$ freezer and immediately placed in a $2 \mathrm{ml}$ glass dounce homogenizer (Kimble-Kontes) containing ice-cold CERI buffer (for cytoplasmic fraction) with $1.5 \times$ protease inhibitors, $1 \times$ EDTA, and $2 \times$ phosphatase inhibitors (PIERCE). Samples were then homogenized using 11 strokes with pestle $B$ and 10 strokes with pestle $A$, and transferred to $0.5 \mathrm{ml}$ tubes. After sitting on ice for $10 \mathrm{~min}$, samples were briefly vortexed and spun at $16000 \times g$ at $4^{\circ} \mathrm{C}$ for $5 \mathrm{~min}$. Samples were then placed back on ice and supernatant was collected and saved for cytoplasmic protein analysis. Next, NERI buffer (for nuclear fraction), containing $1.5 \times$ protease inhibitors, $1 \times$ EDTA, and $2 \times$ phosphatase inhibitors (PIERCE) was added to the cell pellet. Samples were vortexed every $10 \mathrm{~min}$ for $40 \mathrm{~min}$ and spun at $16000 \times g$ at $4^{\circ} \mathrm{C}$ for $10 \mathrm{~min}$. The supernatant (containing nuclear enriched protein fraction) was collected and stored for later analysis.

Western blot. Protein concentrations were determined using BSA method (PIERCE). Kaleidoscope protein standards (Bio-Rad) and CA1/CA3 samples $(20 \mu \mathrm{g} / \mathrm{lane})$ were loaded on $4-15 \%$ gradient gels (Bio-Rad) and run for $1 \mathrm{~h}$ at 120 V. Proteins were then transferred to PDVF membranes (Amersham) overnight at $50 \mathrm{~V} / 4^{\circ} \mathrm{C}$. Blots were then stained with Ponceau $S$ and photocopied. Blots were washed $5 \mathrm{~min}$ in T-BST and subsequently blocked in T-BST (7\% milk) for $1 \mathrm{~h}$ Primary antibodies were then applied to blots overnight at $4^{\circ} \mathrm{C}$ (Table 1), washed three times with TBS, and secondary antibodies applied for $2 \mathrm{~h}$ at room temperature. Blots were then developed using ECL Plus Western Blot Detection Kit (Amersham) on biomax film (Kodak). Blots were scanned using 6500 scanner (Bio-Rad), and densitometry determined using UNSCAN IT software (silk scientific).
Immunofluorescence. A 28-month-old Fisher 344/BN rat was anesthetized and perfused with $4 \%$ paraformaldehyde. The brain was removed, placed in paraformaldehyde for $1 \mathrm{~h}$, and transferred to $30 \%$ sucrose solution for $72 \mathrm{~h}$. After fixation, the brain was embedded in optimal cutting compound and $8 \mu \mathrm{m}$ coronal sections were made using a cryostat. Slices were collected on Superfrost Plus glass slides (Fisher), and allowed to air dry for $1 \mathrm{~h}$. Slides were then washed with PBS and permeabilized with $0.05 \%$ TritonX-100/PBS for $15 \mathrm{~min}$. Slides were washed again in PBS and treated with $1 \%$ SDS/PBS for 5 min for mild antigen retrieval. Sections were then washed in PBS, blocked with $20 \%$ goat serum (in $1 \%$ BSA PBS) for $2 \mathrm{~h}$, and incubated overnight (at $\left.4^{\circ} \mathrm{C}\right)$ in $3 \%$ goat serum PBS containing rabbit antiphospho or total FOXO3a + mouse anti-neuronal tubulin III or rabbit anti-PHLPP1. Slides were then washed with PBS and incubated with secondary antibodies (Alexa Fluor goat anti-rabbit 594/goat anti-mouse 488; Invitrogen) for $1.5 \mathrm{~h}$. Slides were then stained with $3 \%$ Sudan Black B in $70 \%$ ethanol for 10 min to remove lipofuscin autofluorescence. Finally, slides were mounted (Prolong Gold Anti-Fade with DAPI; Invitrogen) and images were taken on an Axiovert 40 CFR fluorescent microscope (Zeiss).

Statistical analysis. Western blot densitometry was analyzed using three way ANOVA (NCSS Statistical Software); data significant at $P<0.05$. Post hoc analysis was carried out using Fisher LSD test. All graphs were produced using Prism software (Silk Scientific).

Acknowledgements. This research was supported by the $\mathrm{NIH}$ : (1) Neurobiology of Aging Training Grant 2-T32-AG000196-16A1 (2) R01AG014979-09 and (3) Evelyn F. McKnight Brain Research Grant.

1. Hof PR, Morrison JH. The aging brain: morphomolecular senescence of cortical circuits. Trends Neurosci 2004; 27: 607-613.

2. Kadar T, Dachir S, Shukitt-Hale B, Levy A. Sub-regional hippocampal vulnerability in various animal models leading to cognitive dysfunction. J Neural Transm 1998; 105: 987-1004.

3. Korf ES, White LR, Scheltens P, Launer LJ. Midlife blood pressure and the risk of hippocampal atrophy: the Honolulu Asia aging study. Hypertension 2004; 44: 29-34.

4. Back T, Hemmen T, Schuler OG. Lesion evolution in cerebral ischemia. J Neurol 2004; 251: 388-397.

5. Noda A, Ohba H, Kakiuchi T, Futatsubashi M, Tsukada H, Nishimura S. Age-related changes in cerebral blood flow and glucose metabolism in conscious rhesus monkeys. Brain Res 2002; 936: 76-81.

6. Schmidt-Kastner R, Freund TF. Selective vulnerability of the hippocampus in brain ischemia. Neuroscience 1991; 40: 599-636. 
7. Ouyang YB, Voloboueva LA, Xu LJ, Giffard RG. Selective dysfunction of hippocampal CA1 astrocytes contributes to delayed neuronal damage after transient forebrain ischemia. J Neurosci 2007; 27: 4253-4260.

8. De Jong GI, Farkas E, Stienstra CM, Plass JR, Keijser JN, de la Torre JC et al. Cerebral hypoperfusion yields capillary damage in the hippocampal CA1 area that correlates with spatial memory impairment. Neuroscience 1999; 91: 203-210.

9. West MJ, Kawas CH, Stewart WF, Rudow GL, Troncoso JC. Hippocampal neurons in preclinical Alzheimer's disease. Neurobiol Aging 2004; 25: 1205-1212.

10. Spires TL, Orne JD, SantaCruz K, Pitstick R, Carlson GA, Ashe KH et al. Region-specific dissociation of neuronal loss and neurofibrillary pathology in a mouse model of tauopathy. Am J Pathol 2006; 168: 1598-1607.

11. Fukunaga $\mathrm{K}$, Kawano $\mathrm{T}$. Akt is a molecular target for signal transduction therapy in brain ischemic insult. J Pharmacol Sci 2003; 92: 317-327.

12. Martin D, Salinas $M$, Lopez-Valdaliso R, Serrano $E$, Recuero $M$, Cuadrado A. Effect of the Alzheimer amyloid fragment Abeta(25-35) on Akt/PKB kinase and survival of PC12 cells. J Neurochem 2001; 78: 1000-1008.

13. Xu GG, Deng YQ, Liu SJ, Li HL, Wang JZ. Prolonged Alzheimer-like tau hyperphosphorylation induced by simultaneous inhibition of phosphoinositol-3 kinase and protein kinase C in N2a cells. Acta Biochim Biophys Sin (Shanghai) 2005; 37: 349-354.

14. Brunet A, Park J, Tran H, Hu LS, Hemmings BA, Greenberg ME. Protein kinase SGK mediates survival signals by phosphorylating the forkhead transcription factor FKHRL1 (FOXO3a). Mol Cell Biol 2001; 21: 952-965.

15. Zheng WH, Kar S, Quirion R. Insulin-like growth factor-1-induced phosphorylation of transcription factor FKHRL1 is mediated by phosphatidylinositol 3-kinase/Akt kinase and role of this pathway in insulin-like growth factor-1-induced survival of cultured hippocampa neurons. Mol Pharmacol 2002; 62: 225-233.

16. Borgatti $P$, Martelli AM, Bellacosa A, Casto R, Massari L, Capitani S et al. Translocation of Akt/PKB to the nucleus of osteoblast-like MC3T3-E1 cells exposed to proliferative growth factors. FEBS Lett 2000; 477: 27-32.

17. Wan X, Helman LJ. Levels of PTEN protein modulate Akt phosphorylation on serine 473 but not on threonine 308, in IGF-II-overexpressing rhabdomyosarcomas cells. Oncogene 2003; 22: 8205-8211.

18. Trotman LC, Alimonti A, Scaglioni PP, Koutcher JA, Cordon-Cardo C, Pandolfi PP et al. Identification of a tumour suppressor network opposing nuclear Akt function. Nature 2006; 441: $523-527$

19. Gao T, Furnari F, Newton AC. PHLPP: a phosphatase that directly dephosphorylates Akt, promotes apoptosis, and suppresses tumor growth. Mol Cell 2005; 18: 13-24.

20. Gao T, Brognard J, Newton AC. The phosphatase PHLPP controls the cellular levels of protein kinase C. J Biol Chem 2008; 283: 6300-6311.

21. Kawano T, Morioka M, Yano S, Hamada J, Ushio Y, Miyamoto E et al. Decreased akt activity is associated with activation of forkhead transcription factor after transient forebrain ischemia in gerbil hippocampus. J Cereb Blood Flow Metab 2002; 22: 926-934.

22. Plas DR, Thompson CB. Akt activation promotes degradation of tuberin and FOXO3a via the proteasome. J Biol Chem 2003; 278: 12361-12366.

23. Zheng WH, Kar S, Quirion R. Insulin-like growth factor-1-induced phosphorylation of the forkhead family transcription factor FKHRL1 is mediated by Akt kinase in PC12 cells. J Biol Chem 2000; 275: 39152-39158.
24. Brunet A, Bonni A, Zigmond MJ, Lin MZ, Juo P, Hu LS et al. Akt promotes cell survival by phosphorylating and inhibiting a Forkhead transcription factor. Cell 1999; 96 : 857-868.

25. Michie AM, Nakagawa R. The link between PKC alpha regulation and cellular transformation. Immunol Lett 2005; 96: 155-162.

26. Ziemka-Nalecz M, Zalewska T, Zajac H, Domanska-Janik K. Decrease of PKC precedes other cellular signs of calpain activation in area $\mathrm{CA} 1$ of the hippocampus after transient cerebral ischemia. Neurochem Int 2003; 42: 205-214.

27. Dore S, Kar S, Rowe W, Quirion R. Distribution and levels of [125I]|GF-I, [125I]|GF-II and [125I]insulin receptor binding sites in the hippocampus of aged memory-unimpaired and -impaired rats. Neuroscience 1997; 80: 1033-1040.

28. Lynch $C D$, Lyons $D$, Khan $A$, Bennett $S A$, Sonntag WE. Insulin-like growth factor-1 selectively increases glucose utilization in brains of aged animals. Endocrinology 2001 142: 506-509.

29. Das S, Dixon JE, Cho W. Membrane-binding and activation mechanism of PTEN. Proc Natl Acad Sci USA 2003; 100: 7491-7496.

30. Janssens V, Goris J. Protein phosphatase 2A: a highly regulated family of serine/threonine phosphatases implicated in cell growth and signalling. Biochem J 2001; 353 (Part 3): 417-439.

31. Brognard J, Sierecki E, Gao T, Newton AC. PHLPP and a second isoform, PHLPP2, differentially attenuate the amplitude of Akt signaling by regulating distinct Akt isoforms. Mol Cell 2007; 25: 917-931.

32. Shimizu K, Phan T, Mansuy IM, Storm DR. Proteolytic degradation of SCOP in the hippocampus contributes to activation of MAP kinase and memory. Cell 2007; 128 1219-1229.

33. Yan Q, Rosenfeld RD, Matheson CR, Hawkins N, Lopez OT, Bennett L et al. Expression of brain-derived neurotrophic factor protein in the adult rat central nervous system. Neuroscience 1997; 78: 431-448.

34. Newton IG, Forbes ME, Legault C, Johnson JE, Brunso-Bechtold JK, Riddle DR. Caloric restriction does not reverse aging-related changes in hippocampal BDNF. Neurobiol Aging 2005; 26: 683-688.

35. Zhu W, Bijur GN, Styles NA, Li X. Regulation of FOXO3a by brain-derived neurotrophic factor in differentiated human SH-SY5Y neuroblastoma cells. Brain Res Mol Brain Res 2004; 126: 45-56.

36. Zheng WH, Quirion R. Comparative signaling pathways of insulin-like growth factor-1 and brain-derived neurotrophic factor in hippocampal neurons and the role of the PI3 kinase pathway in cell survival. J Neurochem 2004; 89: 844-852.

37. Kumar N, Afeyan R, Sheppard S, Harms B, Lauffenburger DA. Quantitative analysis of Akt phosphorylation and activity in response to EGF and insulin treatment. Biochem Biophys Res Commun 2007; 354: 14-20.

38. Bellacosa A, Chan TO, Ahmed NN, Datta K, Malstrom S, Stokoe D et al. Akt activation by growth factors is a multiple-step process: the role of the PH domain. Oncogene 1998; 17 : 313-325.

39. Wang R, Brattain MG. AKT can be activated in the nucleus. Cell Signal 2006; 18 1722-1731.

40. Yano S, Tokumitsu $\mathrm{H}$, Soderling TR. Calcium promotes cell survival through CaM-K kinase activation of the protein-kinase-B pathway. Nature 1998; 396: 584-587.

Supplementary Information accompanies the paper on Cell Death and Differentiation website (http://www.nature.com/cdd) 